\title{
Chunky reproduces better? Small rodent fertility and fitness in commercial orchards
}

Linas Balčiauskas

Vitalijus Stirkè

Laima Balčiauskienè

Nature Research Centre, Vilnius, Lithuania

linas.balciauskas@gamtc.It

vitalijus.stirke@gamtc.It

laima.balciauskiene@gamtc.lt

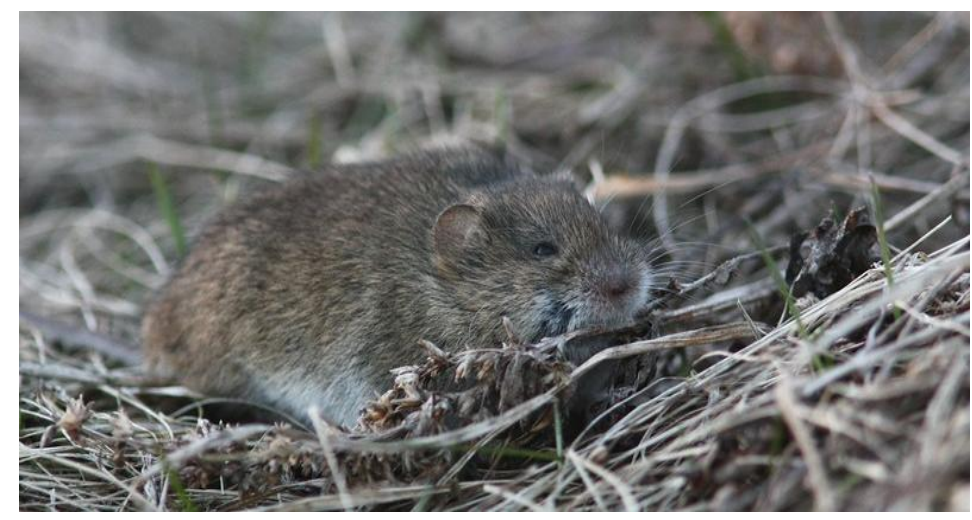




\section{Study sites}

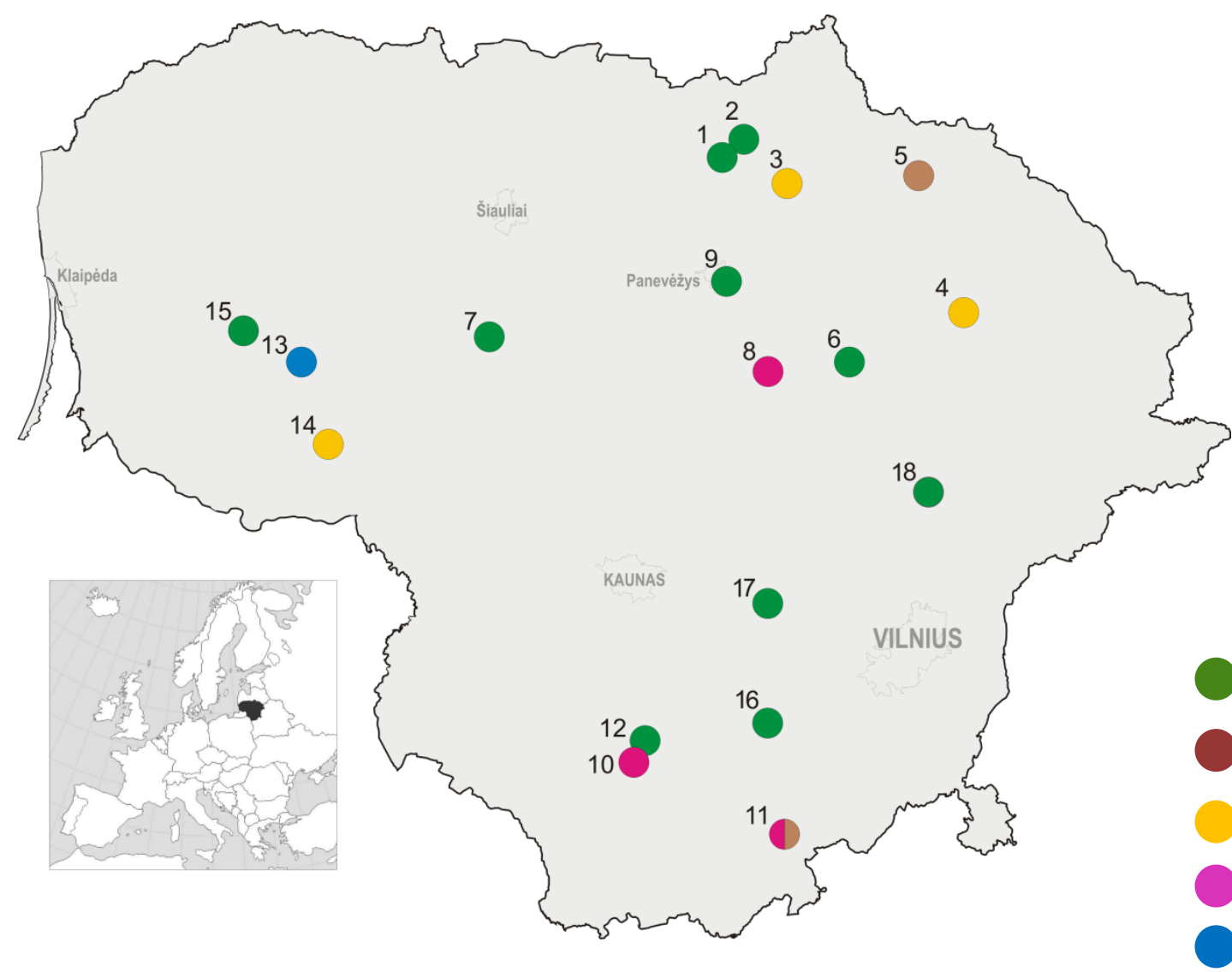

Lithuania:

$65,300 \mathrm{~km}^{2}$

$52.26 \%$ territory is agricultural $33 \%$ arable land

$27 \%$ semi-natural vegetation

42.8 inhabitants $/ \mathrm{km}^{2}$ in 2020

75 mammal species

25,980 ha commercial orchards 9851 ha berry plantations 99,215 tons of production

apple orchards

- plum orchards currant plantations raspberry plantations highbush blueberry plantation 


\section{Study sites:}

Characteristics of habitats

\begin{tabular}{cccccccccccc} 
Crops & $N$ & \multicolumn{3}{c}{ Crop age $^{1}$} & \multicolumn{3}{c}{ Intensity $^{2}$} & \multicolumn{3}{c}{ Control habitat $^{3}$} \\
& & O & MD & Y & H & M & L & MM & NM & FE \\
Apple & 11 & 9 & 1 & 1 & 6 & 2 & 3 & 8 & 2 & 1 \\
Plum & 2 & & 1 & 1 & & 1 & 1 & 1 & 1 & \\
Currant & 3 & & 3 & & & 1 & 2 & 3 & & \\
Raspberry & 3 & & 2 & 1 & 1 & 1 & 1 & 1 & 1 & 1 \\
Highbush blueberry & 1 & & 1 & & 1 & & & 1 & & \\
\hline
\end{tabular}

${ }^{1}$ Age of the orchard: $\mathrm{O}-$ old, $\mathrm{MD}-$ medium, $\mathrm{Y}$-young. ${ }^{2}$ Intensity of agricultural practices on site: $\mathrm{L}-\mathrm{low}, \mathrm{M}-$ medium, $\mathrm{H}$-high. ${ }^{3}$ Control habitat: $\mathrm{MM}$-mowed meadow, $\mathrm{NM}$-non-mowed meadow, FE-forest edge

Intensity of agricultural practices on site:

high

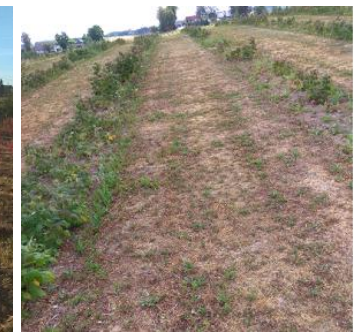

medium

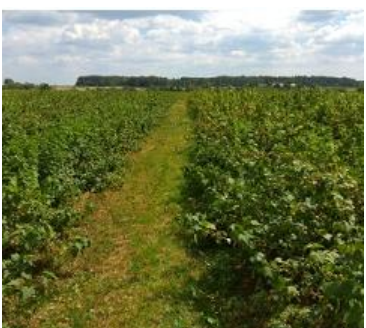

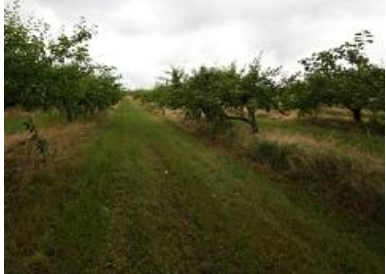

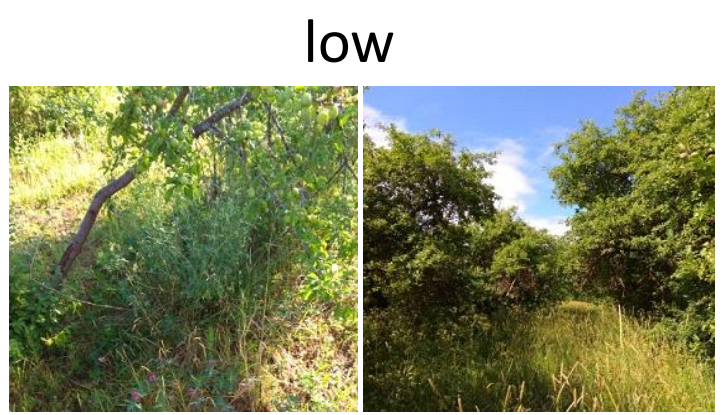




\section{Material and methods}

- $\quad$ Snap trapping, summer and autumn 2018-2020

- Trapping effort 25,503 trap days

- Body condition index, based on body mass and body length

- Dissection

- $\quad$ Reproduction parameters:

(1) number of embryos

(2) number of placental scars

(3) number of corpora lutea

- Reproduction failure:

difference between (1) or (2) and (3)

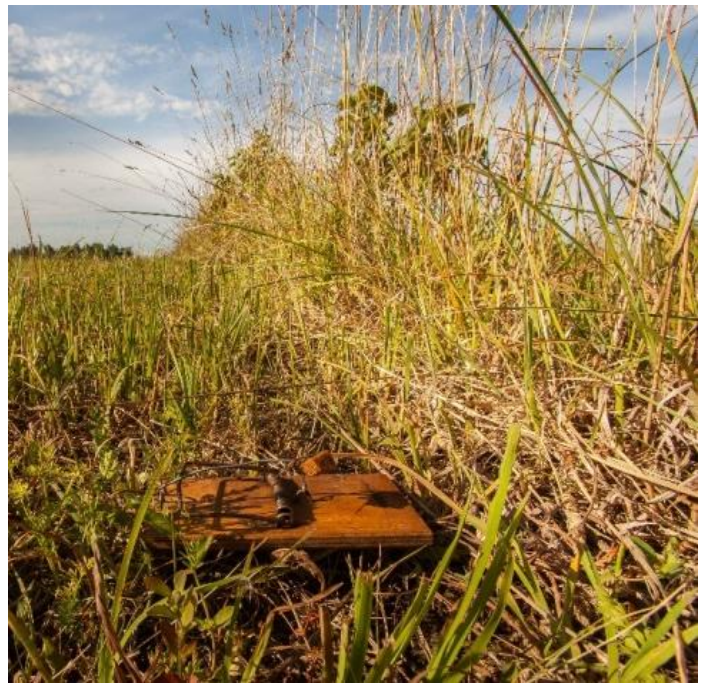




\section{Results}

\section{0 individuals of 11 small mammal species}

\begin{tabular}{|c|c|c|c|c|c|c|c|}
\hline \multirow[b]{2}{*}{ Species } & \multicolumn{3}{|c|}{ Trapped } & \multirow[b]{2}{*}{ BCI } & \multirow[b]{2}{*}{ OLS } & \multirow[b]{2}{*}{ PLS } & \multirow[b]{2}{*}{$\mathrm{BF} \%$} \\
\hline & Total & $\operatorname{Ad}{ }^{n} \partial^{\lambda}$ & $\mathbf{A d} q q$ & & & & \\
\hline Apodemus flavicollis & 374 & 99 & 60 & $3.40^{\mathrm{A}}$ & 5.33 & 5.91 & 12.2 \\
\hline Apodemus agrarius & 346 & 38 & 29 & $3.38^{\mathrm{A}}$ & 6.21 & 6.35 & 21.4 \\
\hline Microtus arvalis & 436 & 41 & 132 & $3.25^{\text {в }}$ & $5.08^{\mathrm{A}}$ & $5.55^{\text {в }}$ & 29.1 \\
\hline Microtus oeconomus & 42 & 8 & 17 & $3.01^{\mathrm{B}}$ & 5.81 & 6.31 & 43.8 \\
\hline Microtus agrestis & 31 & 7 & 14 & $3.29^{\mathrm{B}}$ & 5.00 & 5.55 & 14.3 \\
\hline Myodes glareolus & 164 & 22 & 27 & $3.24^{\mathrm{B}}$ & 5.58 & 5.85 & 29.2 \\
\hline Mus musculus & 5 & & & & & & \\
\hline Micromys minutus & 12 & & & & & & \\
\hline Arvicola terrestris & 1 & & & & & & \\
\hline Sorex araneus & 27 & & & & & & \\
\hline Sorex minutus & 12 & $3.9 \%$ & $f$ all ind & iduals, & ot anal & sed fur & \\
\hline
\end{tabular}

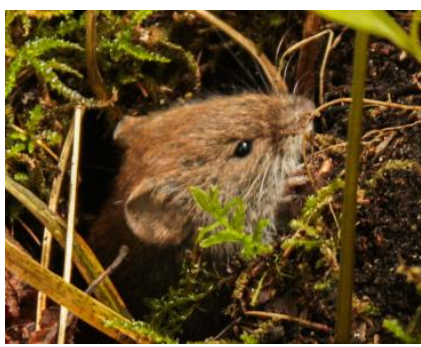

$\mathrm{BCl}$ - body condition index of adult animals

OLS - observed litter size, PLS - potential litter size

$\mathrm{BF} \%$ - percent of breeding failures from number of pregnancies

${ }^{A B} p<0.01,{ }^{a b} p<0.05$

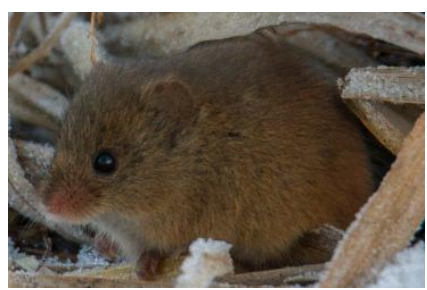




\section{Results}

\section{Proportion of breeders in different seasons}
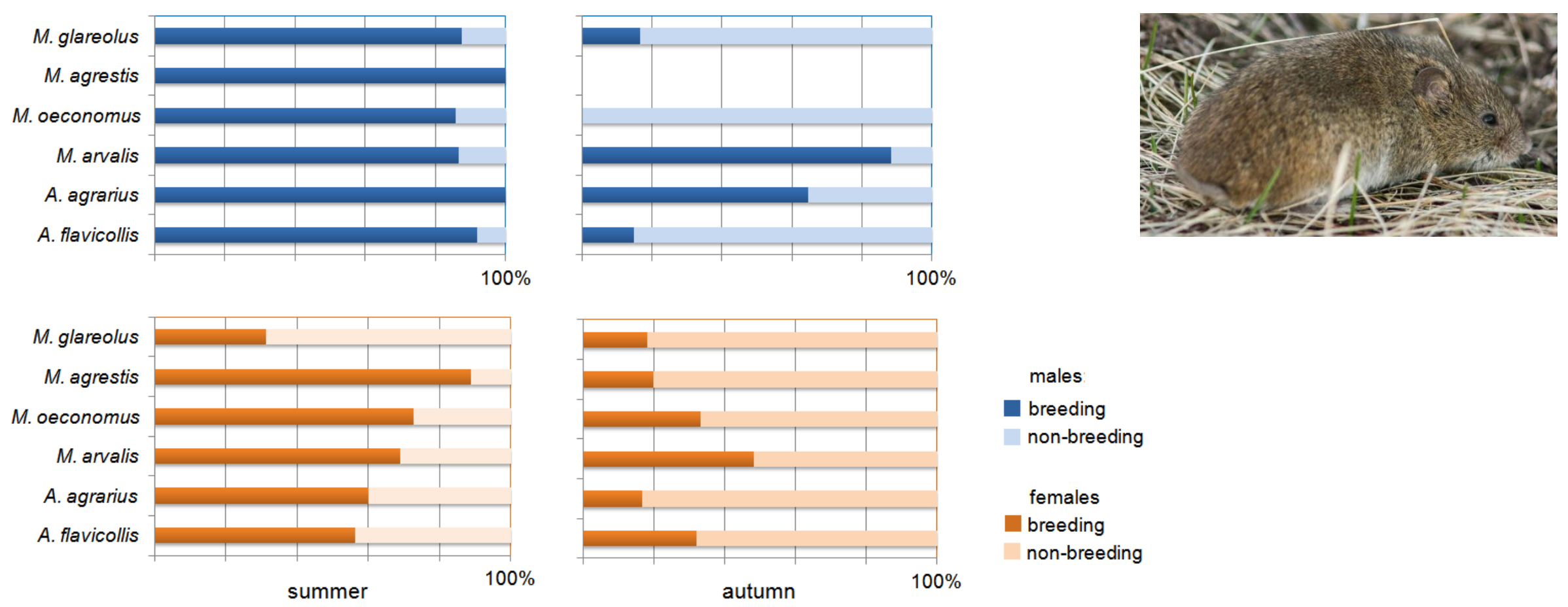

males

breeding

non-breeding

females

breeding

non-breeding 


\section{Results}

Relation of litter size to body mass in summer (top) and autumn (bottom)
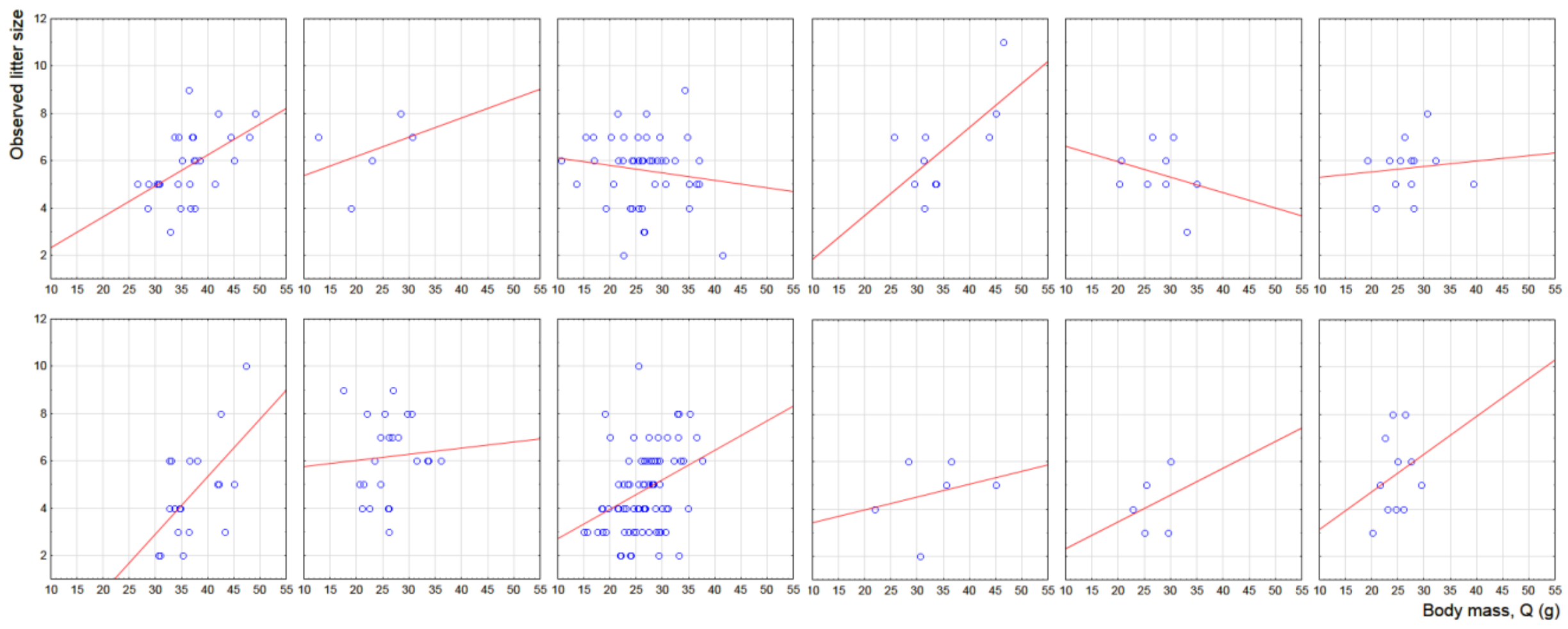


\section{Conclusions}

- Commercial orchards sustain substantial rodent diversity and litter sizes equal to those in adjacent non-agriculture habitats (meadows and forests).

- In 6 most numerous rodent species potential litter sizes exceeded observed

- Breeding failures were observed, the most affected being M. oeconomus, $M$. glareolus and $M$. arvalis. The litter size in these three vole species was smaller in habitats with a higher intensity of agricultural practices.

- The litter size decreased towards winter in all rodents, most significantly in $M$. arvalis and $A$. flavicollis.

- In autumn, litter size and female body mass was positively correlated in all six rodent species.

- Knowledge of reproduction patterns may help in planning sustainable rodent control strategies in orchards and similar habitats. 


\section{Author Contributions:}

Conceptualization, Li.B. and La.B.; methodology, Li.B.; formal analysis, L.iB.; resources, Li.B., La.B., and V.S.; investigation, V.S., Li.B., and La.B.; data curation, La.B. and V.S.; writing Li.B., La.B., and V.S.; project administration, Li.B.; funding acquisition, Li.B.

\section{Funding:}

In 2018 and 2019, this research was funded by the Ministry of Agriculture of the Republic of Lithuania, contract No. MT-18-3.

The APC was funded by the Research Council of Lithuania.

\section{Photo credits:}

All used photos are copyrighted to authors

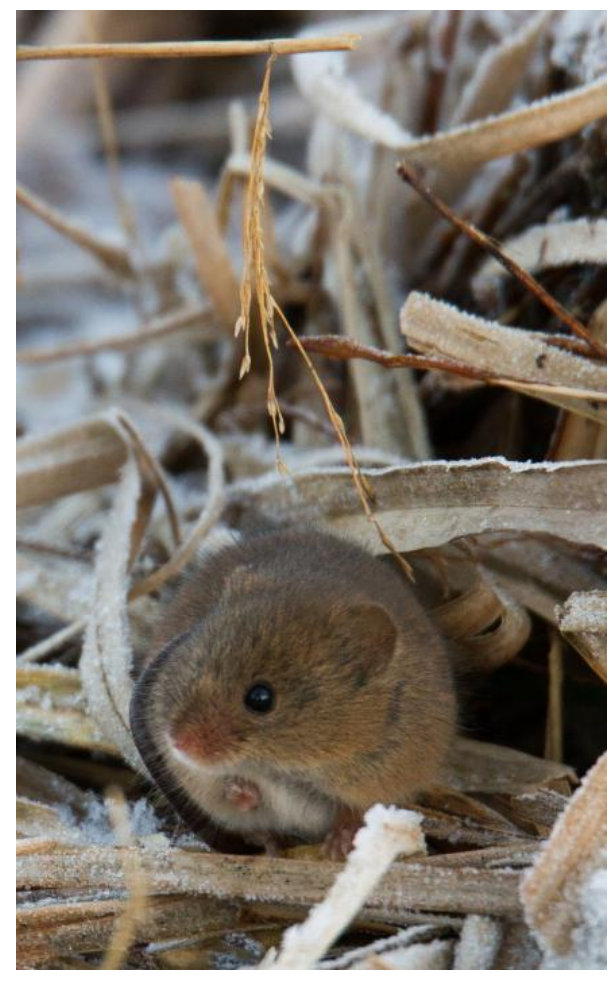

